\title{
Perspectives on the Future Development of Mobile Applications for Dermatology Clinical Research
}

Edward Hadeler (D) - Julie Hong · Megan Mosca • Marwa Hakimi •

Nicholas Brownstone · Tina Bhutani · Wilson Liao

Received: July 15, 2021 / Published online: September 7, 2021

(C) The Author(s) 2021

\section{ABSTRACT}

The COVID-19 pandemic significantly impacted clinical research in dermatology and practices around the country transitioned to teledermatology amid physical distancing requirements. Despite their growing use in teledermatology and clinical care, dermatology applications have not been studied extensively in the research space. The use of mobile applications has the potential to improve the experience of study subjects and physicians and increase the pool of individuals willing to participate in research beyond the pandemic. We discuss the various pros and cons of mobile apps, as well as the necessary components they require to successfully conduct research.

Keywords: AI; Applications; Apps; Artificial intelligence; Clinical research; Mobile; Phone; Remote research; Teledermatology; Telemedicine

\section{Key Summary Points}

Remote research provides several benefits for study participants and researchers, such as reducing travel and time burdens.

Mobile applications for dermatology research require numerous features for optimal use, some of which include educating patients about studies, screening patients, obtaining informed consent, acquiring data, and facilitating high-quality photograph acquisition.

The emergence of machine learning and artificial intelligence may improve the objectivity of photograph evaluation.

Challenges of using applications in research include the cost of purchasing mobile devices, lack of access to highquality internet, and difficulty navigating technologies.

E. Hadeler $(\bowtie) \cdot J$. Hong · M. Mosca · M. Hakimi .

N. Brownstone $\cdot$ T. Bhutani $\cdot$ W. Liao

Department of Dermatology, University of

California, San Francisco, 515 Spruce Street, San

Francisco, CA 94118, USA

e-mail: ehadeler@gmail.com 
LESSONS LEARNED

FROM THE IMPACT OF COVID-19 ON DERMATOLOGY CLINICAL RESEARCH

Clinical research suffered a dramatic decline in participation during the COVID-19 pandemic [1]. Desai et al. reported that 57 dermatologyrelated clinical trials during March, April, and May of 2020 were suspended, withdrawn, or terminated, affecting an estimated 7141 patients [2]. In addition to the many research patients affected during the pandemic, progress across many studies was impeded, potentially leading to delays in drug development. Amid physical distancing requirements, the lack of readily available technologies to conduct studies remotely contributed to significant interruptions.

\section{THE EXPANSION OF TELEDERMATOLOGY AND MOBILE APPLICATIONS IN DERMATOLOGY}

In the clinical care space, many dermatologists transitioned to teledermatology to maintain operations due to physical distancing requirements [3]. Teledermatology can occur synchronously, through the use of live video platforms, termed live-interactive teledermatology; or it can occur asynchronously, through the use of phone or web-based applications (apps), known as store-and-forward teledermatology [4]. Despite a recent resurgence during the COVID-19 pandemic, the use of teledermatology spans decades; its use showed promise in extending care to patients in rural communities and addressing the overall workforce shortage in dermatology [5]. Access to teledermatology for patients has been accelerated by the surge of mobile phone applications. Smartphone ownership has increased from 35\% in 2011 to $81 \%$ in 2019 [6], and the overall convenience of smartphones makes them one of the most amenable devices to facilitate teledermatology. Recent reviews have evaluated the use of mobile-based applications for clinical use $[7,8]$, and studies have also assessed the wide variety of applications available on app stores for consumers [9]. However, despite the rise in smartphone ownership and clinical applications, there is a paucity of mobile applications addressing clinical research in dermatology.

\section{THE BENEFITS OF CONDUCTING REMOTE CLINICAL RESEARCH THROUGH TECHNOLOGY}

Remote research provides several potential benefits for study participants and researchers. It ensures that trials will be protected from interruption due to future pandemics. Importantly, it may increase accessibility to patients who face barriers to participating in research trials. In 2018, a study conducted by Borno et al., which reviewed the travel requirements for 1600 research patients, found that the median unidirectional distance traveled to a study site was 25.8 miles, increasing to as much as 39.4 miles for certain trials [10]. Of note, patients living in low-income areas were cited as one of the groups having the highest travel burden [10]. Compounding this issue, patients of low socioeconomic status may often have busy work schedules and find it difficult to take time off to come to clinics for required monthly, and sometimes weekly, research visits. Lack of private transportation, childcare, and inflexible work schedules have resulted in higher no-show rates for minority and Medicaid patients $[11,12]$. These barriers are further evident in clinical research, where a low number of nonwhite patients have been cited in psoriasis trials [13]. With fewer travel requirements, more patients may have the flexibility to enroll in a larger number of studies, improving the generalizability of clinical research.

\section{IMPORTANT COMPONENTS OF DERMATOLOGY RESEARCH APPS FOR REMOTE STUDIES}

Mobile applications for dermatology research are likely to be impactful for the conduct of 
clinical trials; however, these applications can potentially be used for other studies, including cross-sectional and cohort studies. Mobile apps for clinical research require several features for optimal use. These apps should be able to educate the patient about the study, screen patients for eligibility, and obtain informed consent. Additionally, the app should be able to gather a variety of information, including surveys, personal health data, and demographics. Further, they should allow for accessible communication with the study team for risk assessments.

The application should facilitate high-quality photograph acquisition for disease severity assessments. Patients should receive guidance and assistance from the application to take photographs with proper positioning and lighting. Finally, these photographs should be uploaded and organized on a web-based platform where the study team can evaluate them.

The emergence of machine learning and artificial intelligence (AI) to evaluate clinical images, such as those taken from a smartphone, may improve the objectivity of these photographs in the future [14]. Algorithms are being developed to objectively rate clinical characteristics, such as skin erythema, which is a significant component of scoring in psoriasis and atopic dermatitis severity. As machine learning becomes further integrated into evaluating images, this technology can be incorporated into monitoring patient disease status objectively [15].

\section{THE CHALLENGES OF USING MOBILE APPS FOR REMOTE CLINICAL RESEARCH}

While reduced travel and overall convenience serve as potential benefits to remote research, other factors may present barriers to research access. The substantial cost of purchasing a mobile device that has a high-quality camera can be prohibitive. Lack of access to high-quality internet may present a challenge for some individuals. Reports show that only $56 \%$ of U.S. adults who earn less than $\$ 30,000$ have access to home broadband internet [16]. Reduced personal interactions with providers may lead to decreased study motivation. Difficulties navigating technologies and potential delays in communication may also frustrate patients. In a previous evaluation of clinical care apps, participants from a racially and ethnically diverse population completed only $43 \%$ of tasks across 11 apps, citing lack of confidence with technology and difficulty understanding design features as issues [17]. Therefore, research apps should be inclusive of cultural, digital literacy, and language needs in their development.

To obtain high-quality photographs, patients will have to be instructed on how to properly acquire photographs in standardized positions for severity scoring. These photographs will have to be taken under good lighting and, sometimes, in a handsfree manner. Other logistical challenges include activities conducted outside the home. These involve obtaining bloodwork and arranging for receipt of medications; however, these activities can be achieved during more flexible hours. Appropriate data infrastructure and management are also necessary for patient privacy. Finally, automated algorithms to evaluate images for clinical characteristics may be prone to error if not evaluated in different racial and ethnic groups representing a spectrum of skin tones. Therefore, it is important that these algorithms are trained to characterize various skins of color.

The advantages and limitations of using mobile apps for clinical research with regard to accessibility, recruitment, screening, skin evaluation, adverse events, compliance, and data are summarized in Table 1.

\section{DEVELOPMENT OF DERMATOLOGY RESEARCH MOBILE APPS BEYOND THE PANDEMIC}

We anticipate the development and use of phone applications in research to expand beyond the pandemic. Remotely driven research modalities are being actively developed within the medical industry to augment and enhance traditional research methods. Two corporations, Medable Inc. (Palo Alto, CA, USA) and Science 37 (Los Angeles, CA, USA), have received substantial investments during the 
Table 1 Advantages and limitations of mobile applications in dermatology research

\begin{tabular}{|c|c|c|}
\hline $\begin{array}{l}\text { Research } \\
\text { study } \\
\text { components }\end{array}$ & Advantages & Limitations \\
\hline \multirow[t]{2}{*}{ Accessibility } & Reduced travel and time barriers & High-quality internet access required \\
\hline & Patients can participate in more studies & $\begin{array}{l}\text { Phone with camera of sufficient quality } \\
\text { required }\end{array}$ \\
\hline Recruitment & $\begin{array}{l}\text { Possibility of displaying studies tailored to patient } \\
\text { characteristics }\end{array}$ & $\begin{array}{l}\text { Certain populations of individuals may } \\
\text { not feel comfortable with mobile app- } \\
\text { based information }\end{array}$ \\
\hline Screening & $\begin{array}{l}\text { Efficient screening process without need for in-person } \\
\text { appointment }\end{array}$ & $\begin{array}{l}\text { Evaluation of skin must occur through } \\
\text { photographs or video }\end{array}$ \\
\hline $\begin{array}{l}\text { Skin } \\
\text { evaluation }\end{array}$ & $\begin{array}{l}\text { Integration of AI and standardized image capture; possibility } \\
\text { of more objective image evaluation in patients with skin of } \\
\text { color }\end{array}$ & $\begin{array}{l}\text { Variable photograph quality } \\
\text { Taking proper standardized photographs } \\
\text { of self may be challenging }\end{array}$ \\
\hline Adverse events & $\begin{array}{l}\text { Patients can report adverse events with ease } \\
\text { Study team can triage adverse events }\end{array}$ & $\begin{array}{l}\text { Potential for missed adverse events that } \\
\text { could be elicited on in-person interview }\end{array}$ \\
\hline Compliance & $\begin{array}{l}\text { Efficiently track patient progress on study assessments (i.e., } \\
\text { questionnaires) }\end{array}$ & $\begin{array}{l}\text { Reduced face-to-face contact with study } \\
\text { team may reduce compliance }\end{array}$ \\
\hline \multirow[t]{2}{*}{ Data } & Reduced paperwork and data input burden on research staff & Cost of data storage \\
\hline & Extract and analyze data promptly & Maintenance of data security/encryption \\
\hline
\end{tabular}

AI Artificial intelligence

COVID-19 pandemic to design and roll out phone and web applications intended for conducting clinical research, with the goal of using these applications in the future [18, 19].

The use of mobile applications in the clinical research space presents great promise to improve the experience for study subjects and physicians and to increase the diversity of individuals willing to participate. However, potential limitations also exist, and research applications should be designed with these limitations in mind. Further studies are needed to evaluate the various strengths and shortfalls of these applications once they are developed.

\section{ACKNOWLEDGEMENTS}

Funding. No funding or sponsorship was received for this study or publication of this article.

Authorship. All named authors meet the International Committee of Medical Journal Editors (ICMJE) criteria for authorship of this article, take responsibility for the integrity of the work as a whole, and have given their approval for this version to be published.

Authorship Contributions. Edward Hadeler contributed to the concept, design, drafting, and editing of the manuscript. Julie Hong contributed to the drafting and editing of the manuscript. Megan Mosca contributed to the 
drafting and editing of the manuscript. Marwa Hakimi contributed to the editing of the manuscript. Nicholas Brownstone contributed to the editing of the manuscript. Tina Bhutani contributed to the concept and editing of the manuscript. Wilson Liao contributed to the concept, design, drafting, and editing of the manuscript. All authors discussed the results and contributed to the final manuscript.

Disclosures. Tina Bhutani has received research funding from Abbvie, Celgene, Galderma, Janssen, Pfizer, Regeneron, and Sun; and has served as an advisor for Abbvie, BoehringerIngelheim, Bristol Myers Squibb, Pfizer, Leo, Lilly, and Novartis. Wilson Liao has received research grant funding from Abbvie, Amgen, Janssen, Leo, Novartis, Pfizer, Regeneron, and TRex Bio. After completion of this manuscript Edward Hadeler is affiliated with the University of Miami Miller School of Medicine; Julie Hong is affiliated with Penn State College of Medicine; Megan Mosca is affiliated with the University of Nevada, Reno School of Medicine; and Nicholas Brownstone is affiliated with Society for Cutaneous Medicine, New York. Marwa Hakimi has nothing to disclose.

Compliance with Ethical Guidelines. This article is based on previously conducted studies and does not contain any new studies with human participants or animals performed by any of the authors.

Open Access. This article is licensed under a Creative Commons Attribution-NonCommercial 4.0 International License, which permits any non-commercial use, sharing, adaptation, distribution and reproduction in any medium or format, as long as you give appropriate credit to the original author(s) and the source, provide a link to the Creative Commons licence, and indicate if changes were made. The images or other third party material in this article are included in the article's Creative Commons licence, unless indicated otherwise in a credit line to the material. If material is not included in the article's Creative Commons licence and your intended use is not permitted by statutory regulation or exceeds the permitted use, you will need to obtain permission directly from the copyright holder. To view a copy of this licence, visit http://creativecommons.org/licenses/by$\mathrm{nc} / 4.0 /$.

\section{REFERENCES}

1. Gelfand JM, Hefele BE. Clinical research after COVID-19: embracing a new normal. J Investig Dermatol. 2021;141(3):481-3. https://doi.org/10. 1016/j.jid.2020.08.004.

2. Desai S, Manjaly P, Lee KJ, Li SJ, Manjaly C, Mostaghimi A. The impact of COVID-19 on dermatology clinical trials. J Investig Dermatol. 2021;141(3): 676-8. https://doi.org/10.1016/j.jid.2020.06.032.

3. The Dermatologist. COVID-19 and teledermatology: the past, present, and future. https://www.thedermatologist.com/article/covid-19-andteledermatology-past-present-future. Accessed 24 Apr 2021.

4. Pasquali P, Sonthalia S, Moreno-Ramirez D, et al. Teledermatology and its current perspective. Indian Dermatol Online J. 2020;11(1):12-20. https://doi. org/10.4103/idoj.IDOJ_241_19.

5. Norton SA, Burdick AE, Phillips CM, Berman B. Teledermatology and underserved populations. Arch Dermatol. 1997;133(2):197-200.

6. Franciosi EB, Tan AJ, Kassamali B, O'Connor DM, Rashighi M, LaChance A. Response to the influence of teledermatology on health care access and equity. J Am Acad Dermatol. 2021;84(4):e221-2. https://doi.org/10.1016/j.jaad.2020.12.037.

7. Glines KR, Haidari W, Ramani L, Akkurt ZM, Feldman SR. Digital future of dermatology. Dermatol Online J. 2020;26(10):13030/qt75p7q57j.

8. Clark AK, Bosanac S, Ho B, Sivamani RK. Systematic review of mobile phone-based teledermatology. Arch Dermatol Res. 2018;310(9):675-89. https:// doi.org/10.1007/s00403-018-1862-4.

9. Tongdee E, Markowitz O. Mobile app rankings in dermatology. Cutis. 2018;102(4):252-6.

10. Borno HT, Zhang L, Siegel A, Chang E, Ryan CJ. At what cost to clinical trial enrollment? A retrospective study of patient travel burden in cancer clinical trials. Oncologist. 2018;23(10):1242-9. https://doi. org/10.1634/theoncologist.2017-0628.

11. Syed ST, Gerber BS, Sharp LK. Traveling towards disease: transportation barriers to health care 
access. J Community Health. 2013;38(5):976-93. https://doi.org/10.1007/s10900-013-9681-1.

12. Dantas LF, Fleck JL, Cyrino Oliveira FL, Hamacher S. No-shows in appointment scheduling-a systematic literature review. Health Policy. 2018;122(4):412-21. https://doi.org/10.1016/j. healthpol.2018.02.002.

13. Reddy VD, Myers BA, Chan SY, et al. A review of current phase III clinical trials of plaque psoriasis: under-representation of nonwhite participants and need for reform. Br J Dermatol. 2021;184(2): 348-50. https://doi.org/10.1111/bjd.19468.

14. Chan S, Reddy V, Myers B, Thibodeaux Q, Brownstone N, Liao W. Machine learning in dermatology: current applications, opportunities, and limitations. Dermatol Ther (Heidelb). 2020;10(3):365-86. https://doi.org/10.1007/s13555-020-00372-0.

15. Partl R, Jonko B, Schnidar S, et al. 128 SHADES OF RED: objective remote assessment of radiation dermatitis by augmented digital skin imaging. Stud Health Technol Inf. 2017;236:363-74.
16. Anderson M. Mobile technology and home broadband 2019. Pew Research Center. 2019. https://www.pewresearch.org/internet/2019/06/13/ mobile-technology-andhome-broadband-2019/. Accessed 24 Apr 2021.

17. Sarkar U, Gourley GI, Lyles CR, et al. Usability of commercially available mobile applications for diverse patients. J Gen Intern Med. 2016;31(12): 1417-26. https://doi.org/10.1007/s11606-0163771-6.

18. Hall C. Medable secures $\$ 78 \mathrm{M}$ series $\mathrm{C}$ extension to scale digital clinical trials program. Crunchbase News. 2021. https://news.crunchbase.com/news/ medable-secures-78m-series-c-extension/. Accessed 24 Apr 2021.

19. Adams B. Virtual trial specialist and big pharmabacked Science 37 nabs $\$ 40 \mathrm{M}$ funding round. Fiercebiotech. 2020. https://www.fiercebiotech. $\mathrm{com} / \mathrm{cro} /$ virtual-trial-specialist-and-big-pharmabacked-science-37-nabs-40m-funding-round. Accessed 24 Apr 2021. 